\title{
Clinical Features and Illness Severity in Children with COVID-19: A Systematic Review and Meta-Analysis
}

\author{
Lizeth Gutiérrez-Canales ${ }^{1}$, José Vázquez-Cobá ${ }^{2}$, Loreli Álvarez-Díaz ${ }^{2}$, Victoria \\ Guillén-Vázquez ${ }^{3}$, Armando Maldonado-Cobá ${ }^{4}$, Fernando Loyola-Nieto ${ }^{4}$, Alfonso \\ Reyes-Lopez ${ }^{5}$, and RODOLFO N Jimenez-Juarez ${ }^{5}$ \\ ${ }^{1}$ University of Guanajuato - Leon Campus \\ ${ }^{2} \mathrm{UNAM}$ \\ ${ }^{3}$ Universidad Autónoma de Chiapas Facultad de Medicina \\ ${ }^{4}$ Universidad Panamericana - Campus México \\ ${ }^{5}$ Hospital Infantil de Mexico Federico Gomez
}

August 3, 2020

\begin{abstract}
Background Pediatric patients represent approximately $2 \%$ of overall confirmed cases of COVID-19. Illness severity and symptoms differ from adults. Most cases in children are mild but various studies have reported severe and critical cases as well as fatal outcomes. Methods A systematic review and meta-analysis of the available literature was performed. Frequencies were used for reporting categorical variables. Meta-analyses were performed using the binary random effects model for symptoms frequencies in children and illness severity. Results We found 44 studies $(n=6026), 38$ were used for quantitative synthesis to estimate the frequency of symptoms in the pediatric population with Covid-19 and illness severity, 44 were used for qualitative synthesis. The most common symptoms were fever $64 \%$ (CI 95\% 54-72\%), cough $42 \%$ (CI 95\% 37-48\%) and gastrointestinal symptoms like vomit 31\% (CI 95\% 17-47\%) and diarrhea $28 \%$ (CI 95\% 17-40\%). For illness severity 2\% (CI 95\%0-5\%) were severe and 3\% (CI 95\% 1-6\%) were critical. Children <1-year-old had the higher odds of severe/critical cases with an OR of 2.07 (IC95\% 1.40-3.05). All patients were hospitalized, and a total of $10.34 \%$ children admitted to PICU. The mortality rate was $0.16 \%$ (8/487). A total of 141 patients developed PIMS-TS and only one died. Conclusions: Most cases in children were non-severe, nevertheless children less than 1 year had the higher risk of severe/critical cases. Symptoms frequencies encountered from major to minor were fever, cough and gastrointestinal symptoms. More testing in children should be done in order to understand transmission characteristics in the pediatric population.
\end{abstract}

\section{Word count: 248 INTRODUCTION}

The coronavirus disease 2019 (COVID-19) is a new emerging infectious disease reported in December 2019 to the World Health Organization (WHO) by the Chinese health authorities as a new outbreak of pneumonialike cases in Wuhan, China [1,2]. The etiologic agent is the severe acute respiratory syndrome coronavirus 2 (SARS-CoV-2). COVID-19 has turned into a pandemic, up until June 19, 2020, there were 8.24 million confirmed cases and 445,535 deaths worldwide [4].

Pediatric patients represent approximately $2.4 \%$ of the overall confirmed cases [5]. Illness severity spectrum in children is classified as asymptomatic, mild, moderate, severe and critical disease [6], in contrast, adult clinical classification does not include moderate disease [7,8]. Nevertheless, illness severity among children 
is thought to be mainly a mild disease [7,9], various studies have reported severe and critical cases as well as fatal outcomes [10-12] whereas an important proportion of children cases are asymptomatic [13].

The spectrum of disease in pediatric patients has a very heterogeneous behavior unlike adults, mostly of patients develop asymptomatic and mild disease, where fever, cough and gastrointestinal symptoms predominate, but can also develop severe disease, requiring hospitalization and even mechanical ventilation, less frequently compared to adults $(<7 \%)$, recently Multi-systemic Inflammatory Syndrome related to SARSCoV-2 infection has been described how a severe disease in children. [7, 14, 15]

COVID-19 has a different behavior between age groups regarding epidemiological and clinical characteristics, therefore this study aims to provide a qualitative and quantitative analysis to summarize the evidence available in the literature, about epidemiology, illness severity and clinical features among children.

\section{METHODS}

\section{Protocol and registration}

This Systematic Review of Literature followed the recommendations of the Preferred Reporting Items for Systematic Reviews and Meta-Analyses (PRISMA) statement [16].

\section{Eligibility criteria}

We included published and peer-reviewed studies, which were observational, cross-sectional, retrospective, case series, brief reports and letters to the editor that reported clinical features or illness severity among children $(<21 \mathrm{y})$ with COVID-19. Other reviewed items were epidemiological data, pediatric age categories, management, outcomes, imaging and laboratory findings. Due to the limited data of COVID-19 in children outside China, we decided to include letters to the editor from other countries that met the inclusion and exclusion criteria to increase the variability population. Only English language studies were included. Duplicate publications, review articles, case reports, editorials and opinion articles were excluded. We also excluded articles that did not have enough information about children since its main target was the adult population.

\section{Information sources and search strategy}

We conducted a systematic search of studies published from February 18th, 2020 to June 8th, 2020 in PubMed and other databases (ScienceDirect, SpringerLink, Ovid and Google Scholar). We used the MeSH terms; ("COVID-19" [Supplementary Concept]) AND "Child"[Mesh]. The search ended on June 8th, 2020. Two different searchers independently evaluated the search results (GCLG, VCJA). Disagreements were resolved by a third searcher (ADL).

\section{Study selection and data selection}

First, we appraised the screening strategy by title and abstract, then full texts were evaluated by inclusion criteria, and finally peer reviewed. For each study we obtained the following variables: author's name, country, year of publication, total number of patients, sex distribution, pediatric age categories (divided according agreement between studies as follows: $<1 \mathrm{y}, 1-5 \mathrm{y}, 6-10 \mathrm{y}$ and $>10 \mathrm{y}$ ), previous contact with a family member infected, mean incubation period, diagnosis by real-time polymerase chain reaction (RTPCR) and serum antibodies levels (IgM, IgG), illness severity, clinical features, number of patients admitted into the pediatric intensive care unit (PICU), complications, image-laboratory findings and management. We included the analysis of the Pediatric Inflammatory Multisystem Syndrome Temporally Associated with SARS-Cov-2 (PIMS-TS) and their own variables like clinical findings, complications, severity and mortality.

Definition for illness severity, was based on the clinical classification of COVID-19 in children, proposed by Shen K et al. [6] and definition of PIMS-TS reviewed by The Royal College of Pediatrics and Child Health (RCPCH) $[17,18]$. Available inSupplementary Material .

\section{Risk of bias in individual studies}


Two researchers (GCLG and VCJA) assessed the risk of bias by using the appraisal tool to assess the quality of cross-sectional studies (AXIS).Table 1 . [19].

\section{Statistical Analysis}

Meta-analysis of prevalence estimations was done using the Stata commandmetaprop, that allows computation of $95 \%$ confidence intervals using the score statistic and the exact binomial method and incorporates the Freeman-Tukey double arcsine transformation of proportions to stabilize the variance and to achieve approximate normality [20]. Meta-analysis of effect sizes that account for the association between age groups and severity of the disease were done by means of random-effects models and the method used for estimating between-study variability was restricted maximum likelihood. Additionally, using $\mathrm{I}^{2}$ index was obtained to measure heterogeneity.

\section{RESULTS}

A total of 287 articles were found in the systematic review of the literature (254 in PubMed and 38 in other databases). After removing duplicates, screening by title and abstract, 58 articles were selected for full-text evaluation, 14 were excluded for different reasons. A total 44 articles were chosen for qualitative analysis, 38 for quantitative analysis of clinical findings [17,18, 21-30,32-38,40,42-48,50-52,54-58,60,62] and 43 for quantitative analysis of illness severity severity[17,18,31-56,58,60-62].Figure 1. All were observational studies, twenty-six studies were done in China [21-37,], five were from USA [18,39,50,59,60], five from Italy $[40,44,47,56,57]$, three from Spain $[49,51,61]$, two from France [48,62], one was made in Malaysia [38], Iraqi Kurdistan [41] and UK [17]. The main characteristics of included studies and individual risk of bias are shown in Table 1 .

Epidemiology

A total of 6026 children with confirmed or suspected COVID-19 were included. $55.25 \%$ cases were males. Age ranged from newborn to 21 years, a total of 5754 patients were distributed as follows: $19.09 \%$ ( $<1$ year), $17.18 \%$ (1-5 years), $20.17 \%$ (6-10 years) and $43.53 \%$ (>10 years) $[21,27,29-35,38-48,50-52,54,56,59,61]$. Supplementary Material . Mean incubation period was $6.33( \pm 2.48)$ days. Fourteen studies noted 165 patients with comorbidities $[17,21,26,27,30,34,39,41,47-49,51,57]$, the most common are neoplasms, overweight and obesity, cardiac diseases, neurological and chronic respiratory diseases, mostly asthma. In addition 5 studies reported 6 severe/critical cases with comorbidities, a teenager with obesity, one scholar with acute lymphoblastic leukemia, 3 infants with congenital cardiac disease, one infant with chronic wheezes. $[21,27,30,49,58]$. A total of $68.48 \%$ cases $(526 / 768)$ had previous contact with an infected family member. Diagnosis was performed with real time polymerase chain reaction (RT-PCR) by nasopharyngeal swab in 1656 patients, 110 patients were diagnosed by serum antibodies (IgM, IgG). [17,18,44,48,61,62]. Seven studies assessed the presence of SARS-CoV-2 in stools [25,29,30,32,45,48,61], finding 18.82\% (32/170) positive cases. All RT-PCR tests in stool samples were made in confirmed cases of COVID-19.

Illness severity

Illness severity distribution among 3175 cases (2 lost) [31] were: asymptomatic 6\% (CI95\% 3-10\%), $\mathrm{I}^{2} 84.92 \%$ $\mathrm{p}<0.001$ (all of them diagnosed after contact with family member), mild disease $28 \%$ (CI 95\% 19-38\%) $\mathrm{I}^{2}$ $92.05 \% \mathrm{p}<0.001$, moderate disease $33 \%$ (CI 95\% 24-43\%) $\mathrm{I}^{2} 92.20 \% \mathrm{p}<0.001$, severe illness $2 \%$ (CI $95 \%$ $0-5 \%)^{2} \quad 77.52 \% \mathrm{p}<0.001$ and critical disease $3 \%$ (CI 95\% 1-6\%) with $\mathrm{I}^{2} 90.04 \%$ and $\mathrm{p}<0.001$ Figure 2 .

Hence approximately $89.73 \%$ cases in pediatric population were non-severe. Pooled Odds Ratio (OR) of severe or critical illness in children $<1 \mathrm{y}$ was 2.07 (CI 95\% 1.40-3.05) $\mathrm{p}<0.001$, but heterogeneity statistics were unable to calculate since a single study weighs almost $100 \%$ and in patients $>10 \mathrm{y}$ pooled OR was 0.75 (CI 95\% 0.16-3.43) but it was not statistically significant.

\section{Figure 3}

Clinical Manifestations 
Fever was found to be the most frequent symptom with $64 \%$ (CI $95 \% 54 \%-72 \%$ ), $\mathrm{I}^{2} 88.18 \%$ and $\mathrm{p}<0.001$, followed by cough $42 \%$ (CI $95 \% 37 \%-48 \%$ ) I $\mathrm{I}^{2} 59.54 \%$ and $\mathrm{p}<0.001$, vomit $31 \%$ (CI $95 \% 17-47 \%$ ), I ${ }^{2} 94.42 \%$ $\mathrm{p}<0.001$ and diarrhea $28 \%$ (CI 95\% 17\%-47\%) I² 92.67\%, p <0.001. Figure 4.Abdominal pain and constipation $27 \%$ (CI $95 \% 12 \%-45 \%$ ) I ${ }^{2}$ of $95.32 \%$ p $<0.001$, rhinorrhea $19 \%$ (CI 95\% 12\%-28\%), I ${ }^{2} 79.74 \% \%$ $\mathrm{p}<0.001$, fatigue and myalgia 15\% (CI 95\% 5\%-27\%) $\mathrm{I}^{2}=93.03 \% \mathrm{p}<0.001$, tachypnea $13 \%$ (CI $95 \%$ 0\%$45 \%) \mathrm{I}^{2}=88.63 \% \mathrm{p}<0.001$, and less common symptoms were sore throat $10 \%$, (CI $95 \% 4 \%-16 \%$ ) $\mathrm{I}^{2} 82.42 \%$ $\mathrm{p}<0.001$, headache $10 \%$ (CI95\% 4\%-19\%) $\mathrm{I}^{2} 83.30 \%$ and $\mathrm{p}<0.001$ and finally expectoration with a frequency of $9 \%$ (CI95\% 2\%-20\%) I I $^{2}$ 96.65\%, p<0.001. Meta-analysis of other symptoms are shown in Supplementary Material .

Image and laboratory findings

The most important laboratory alterations were: lymphopenia $19.55 \%(124 / 634)[18,21,22,25,26,28-30,34$ $36,40,43-47,52,54,58,60,61]$, lymphocytosis $18.29 \%$ (86/470) [21,22,25,26,29,30,33-36,40,43,45,47,52,58,59], neutrophilia $\quad 17.84 \% \quad(58 / 325) \quad[18,21,22,25,33-36,40,44,45,47,58,62] \quad$ leucopenia $\quad 17.19 \% \quad(\quad 87 / 506)$ $[24,25,28,29,31,32,33,36,38,43,46,48-50,57,61]$ and leukocytosis $16.35 \% \quad(78 / 477) \quad[21,22,25,26,29,30,32-$ $35,40,43,47,52,58,62]$. Pro-inflammatory biomarkers: C-reactive protein increased in $28.55 \%(205 / 718)$ of patients [21-26,28-35,40,43-46,48,52,54,56,58,60-62] and high level of procalcitonin was presented in $18.26 \%$ (76/416) of cases. [21,23,24,26,28-30,33,34,40,46,47,54,60-62]. Supplementary Material .

Other laboratory findings were: D-dimer was increased in $42.85 \%$ (75/175) of patients $[21,23,25,28,29,33,36,39,44,47,61,62]$, alanine- aminotransferase were increased in $22.10 \%(84 / 380)$ $[21,25,26,28,29,33-36,40,44,45,47,52,54,62]$ and high dehydrogenase lactic were presented $21.56 \%(55 / 255)$ of cases $[21,25,27,29,33,34,36,40,45-47,52,61]$. Patients who reported laboratory results were hospitalized therefore we cannot correlate the laboratory findings with illness severity. Supplementary Material .

In respect to image findings a total of $39.61 \%$ (353/891) cases had abnormalities in chest CT scan [21-30,33$37,40,43-47,51,52,54,56,57,58,60,62]$ and $51.10 \%(162 / 317)$ in chest radiography $[18,21-24,29,40,44,52,56-$ $58,62]$ characterized primarily by ground-glass opacities $35.43 \%$ (208/587) [17,21-26,28-30,35,37,40,43,45$47,52,54,60,62]$. In some articles the imaging studies were taken from all hospitalized patients, including asymptomatic, in others studies only from those with more severe symptoms.

Bilateral compromise was seen in $34.82 \%$ cases $156 / 448[18,22,23,27,29,30,34,35,37,40,43-46,54,60]$ and $25.58 \%$ (98/383) cases had unilateral involvement [21,26,27,29,30,33-35,40,43-46,54].Supplementary Material .

Management

Patients were treated with interferon, antivirals (lopinavir-ritonavir), steroids and immunoglobulin. So far, we cannot evaluate effectivity of treatments on the outcomes because all studies are observational and not reported individual or aggregate outcomes.

Complications and outcomes

Coinfection with other pathogen was seen in16.77\% (104/620) of cases $[18,21,22,26,27,30,35,38,43,45,49,56,58,60]$, the most reported wasMycoplasma pneumoniae in $21.95 \%$ $(72 / 328)$ cases $[26,27,30,34,35,43,45]$, Influenza A \& B virus and syncytial respiratory virus were encountered in 4,7 and 8 patients, respectively $[21,26,30,49,56]$ Also, Sun D et al. reported 2 patients who developed sepsis. All patients with co-infection were hospitalized, and a total of $10.34 \%(129 / 1247)$ children admitted to the pediatric intensive care unit. $[17,18,21,27,35,48-50,56,57,58,60,62], 11.56 \%(48 / 415)$ received mechanical ventilation. In five studies reported deaths, the mortality rate was $0.16 \%(8 / 4871)[17,31,39,50,60]$

\section{PIMS-ST in COVID-19.}

Of the 44 studies included in this systematic review, 5 of them specifically described several patients with Kawasaki disease and/or the presence of PIMS-TS in hospitalized patients with history of SARS-CoV-2 infection. $[21,22,47,51,65]$. In the largest case series published by Whitaker et al. [17 ] they included 58 
children, with a median age of 9y, met the criteria for PIMS-TS divided in three patterns; 23 patients presented with fever and elevated pro-inflammatory markers such as RCP, 13 met criteria for complete KD , and 29 presented a toxic shock due to KD or myocardial damage. All patients had fever, 31 developed abdominal pain, 15 headache, 6 sore-throat, 26 patients presented conjunctivitis, 17 had changes in mucus membranes, 9 lymphadenopathy and 9 had swollen extremities. Admission to PICU was required in 29 patients and 25 required mechanical ventilation. All of them had elevated RCP. One patient died. The complete information about these 5 studies is available in Supplementary Material. The most relevant in all studies is the severity of illness, $65.5 \%$ of children were admitted to PICU and one dead.

\section{DISCUSSION}

We conducted a systematic review and meta-analysis with the current evidence available regarding illness severity and clinical features in children (0-21 years), aiming to provide the most frequent COVID-19 characteristics in the pediatric population in order to bring useful information.

The majority of studies included in this systematic review are from China, and eighteen from other countries, this brought more variability in to our study, in comparison to other systematic reviews that only included Chinese population, nonetheless frequencies for epidemiological data, illness severity and clinical features are similar. Most of the patients in the systematic review published by Castagnoli et. al. were $>10$ years old (553) [62]. Similarly, we found the higher number of cases in the teenage population ( $>10$ years old) $44.23 \%$ (2505). The Korean Society of Infectious Diseases has reported a similar age distribution, this might be associated with teenagers being more active than other pediatric groups [64]. Sex distribution is nearly the same $(55.25 \%$ vs $57.35 \%$ cases in males) in our study compared with the systematic review published by De Souza TH.et al. [65]. Above $85 \%$ cases had exposure with a confirmed case in our study. In contrast, a study from Tagarro. A et al. 2020 [49], described 365 suspected cases in children, 41 were positive, 56\% of confirmed cases were females and $39 \%$ of all confirmed cases had previous contact with a confirmed case versus $61 \%$ cases of community transmission. Unlike other respiratory viruses, everything seems to indicate currently, that children are not superspreaders, but they may be the final part of the chain of contagion. This has important implications for school opening policies when the epidemic is controlled locally. [66]

Regarding the illness severity, 95\% cases were non-severe, of whom, $6 \%$ were asymptomatic and $33 \%$ had abnormal findings in chest CT without any serious clinical manifestation, similarly in the systematic review of De Souza TH.et al $96.5 \%$ of patients were non-severe but $14.2 \%$ were asymptomatic [65]. Asymptomatic cases in the pediatric population possess several challenges to public health, however, it is not clear how this cases in children could affect in the velocity of spread of the virus, besides it would be necessary to stratify the viral load of these patients in order to be able to estimate the risk of infection, in a recent the viral load of SARS-CoV-2 was analyzed by patient age, finding no significance difference in viral load between children and adults, thus children could be as infectious as an adult [67]. On the other hand, our results have shown that children develop non-severe disease in most cases in comparison with adults, who present $81 \%$ of mild cases [8] versus almost $95 \%$ in pediatric patients. Moreover, severe cases in adults represent $14 \%$ and critical cases $5 \%$ by contrast only $2 \%$ and $3 \%$ children cases were severe or critical, respectively. Differences in illness severity between children and adults had brought questions about why severe/critical disease frequency in children is low. Garcia-Salido in their letter to the editor discusses some hypotheses about children having more frequently a mild disease. Firstly, the expression of the angiotensin-converting enzyme (ACE) 2 receptor is lower in nasal fluid when the individual is younger, and it could explain the minor frequency of infection and severe disease in pediatric population. The endothelial damage is higher in adults with diabetes and cardiovascular diseases in comparison with healthy children where is practically absent. Finally, the innate immunity in children is well trained by viral community infections and viral vaccines. [68]

Although the focus of the pandemic is on adults, prevention in the pediatric population should not be neglected. Pathak EB et al. [69] estimated the projected numbers of severe pediatric cases in the USA, under different scenarios of cumulative pediatric infection proportion (CPIP), finding 10,993 projected severe/critical cases among children with a 5\% CPIP. Despite non-severe pediatric cases will be the majority, the total number of severe cases will exceed the capacities of a health care system already impaired. 
It is important to emphasize that children are not very symptomatic and not all meet the operational definitions, for example, abdominal pain, vomit and diarrhea have almost the same frequency as cough.Figure 4. Unlike adults, in a meta-analysis published by Rodriguez-Morales AJ et al [70] found that $92 \%$ of adults presented with fever and $63 \%$ with cough, a much higher than children. Other symptoms less frequent in children in contrast with adults are expectoration, fatigue/myalgia, sore throat and dyspnea whereas had equal frequency and gastrointestinal symptoms like diarrhea, vomit and abdominal pain were more frequent in children. Figure $\mathbf{4}$. Hence COVID-19 in children represents a clinical challenge since it is less symptomatic and less severe, making it more difficult to identify. Although the children may spread the virus less, we do not know what will happen when they have more social contact. Unlike Castagnoli study, we observed an increase of severe cases, that are explained by appearance and description of PIMS-TS. Their main clinical features were fever, conjunctivitis, rash, lower limb edema and gastrointestinal symptoms, some of them developing shock and cardiac alterations. Patients presented elevated CRP, ferritin, D-dimer and cardiac enzymes; these clinical findings demonstrated a new phenomenon related to SARS.CoV-2 infection in children. $[17,18]$

Some clinical features of this new syndrome are KD-like but have some differences, for example this syndrome is related to a specific causal agent; SARS-CoV-2 unlike KD whose etiology is still unknown. KD mainly affects children under 5 years but the prevalence of this syndrome is higher in adolescents, the syndrome manifests itself with greater severity, shock, organ failure, heart dysfunction with decreased ejection fraction and higher prevalence in PICU admission compared to KD. [17,48].

We include five studies that referred specifically to this syndrome, the available information is very limited. These are clinical manifestations of severe COVID-19 in children that can lead systemic complications, admission to ICU and even death, therefore it is important that pediatrician take into account this possible presentation in pediatric patients with symptoms similar to KD and optimize early recognition and management to avoid death.

It is important to mention that our study has several limitations such as letters to the editor, including cases series and in-press articles, having patients diagnosed after a confirmed family member and lastly, heterogeneity among studies goes from medium to high. Nevertheless, this study brings useful epidemiological and clinical information about the pediatric population, for instance, children less than 1 year old could be a group of risk since patients $<1 \mathrm{y}$ have twice the risk of developing severe or critical illness compared to other pediatric agesFigure 3. For this reason, public health authorities take to account that children can and will get severe disease and we must be aware for this target population. Children in most of cases will present a mild disease but with an atypical presentation, where clinicians must identify and discard COVID-19 in children, so testing in the pediatric population must increase.

\section{CONCLUSION}

Pediatric patients represent a fundamental population to assess during the COVID-19 pandemic since their characteristics differ from adults. Despite our study has limitations due to the variability among studies, we could summarize the current evidence available, following these key points: A great amount of cases were diagnosed after contact with an infected family member, the majority of cases in children would be nonsevere, nevertheless children less than 1 year old could be at higher risk of develop severe/critical disease. Symptoms frequencies encountered in children from major to minor are fever, cough, vomit, diarrhea and abdominal pain. Clinicians have to be aware of atypical presentations among children. Finally, more studies will be necessary to assess the key role of children could play in based-community transmission, more testing in children should be done in order to understand transmission characteristics in the pediatric population. Caution must be taken in children returning to school, they could be the focus of new outbreaks.

\section{FUNDING}

This study did not receive any external funding.

\section{CONFLICT OF INTERESTS}


The author declared no conflict of interests

\section{REFERENCES}

1. Zhou P, Yang X Lou, Wang XG, et al. A pneumonia outbreak associated with a new coronavirus of probable bat origin. Nature. 2020;579(7798):270-273. doi:10.1038/s41586-020-2012-7

2. Aylward, Bruce (WHO); Liang W (PRC). Report of the WHO-China Joint Mission on Coronavirus Disease 2019 (COVID-19). WHO-China Jt Mission Coronavirus Dis 2019. 2020;2019(February):1624.https://www.who.int/docs/default-source/coronaviruse/who-china-joint-mission-on-covid-19-finalreport.pdf.

3. Ciotti M, Angeletti S, Minieri M, et al. Antimicrobial Section / Review COVID-19 Outbreak: An Overview Keywords COVID-19 · SARS-CoV-2 - Pandemic · Phylogenesis · Protein modeling · Realtime polymerase chain reaction. 2019. doi:10.1159/000507423

4. Practice BB. Coronavirus disease 2019. World Health Organ. 2020;2019(March):2633. doi:10.1001/jama.2020.2633

5. She J, Liu L, Liu W. COVID-19 epidemic: Disease characteristics in children. J Med Virol. 2020;(March):1-8. doi:10.1002/jmv.25807

6. Shen K, Yang Y, Wang T, et al. Diagnosis, treatment, and prevention of 2019 novel coronavirus infection in children: experts' consensus statement. World J Pediatr. 2020;(0123456789). doi:10.1007/s12519-02000343-7

7. Zimmermann P, Curtis N. Coronavirus Infections in Children Including COVID-19: An Overview of the Epidemiology, Clinical Features, Diagnosis, Treatment and Prevention Options in Children. Pediatr Infect Dis J. 2020;39(5). https://journals.lww.com/pidj/Fulltext/2020/05000/Coronavirus_Infections_in_Children_Including.1.aspx.

8. Wu Z, McGoogan JM. Characteristics of and Important Lessons from the Coronavirus Disease 2019 (COVID-19) Outbreak in China: Summary of a Report of 72314 Cases from the Chinese Center for Disease Control and Prevention. JAMA - J Am Med Assoc. 2020;323(13):1239-1242. doi:10.1001/jama.2020.2648

9. Morand A, Fabre A, Minodier P, et al. ScienceDirect COVID-19 virus and children: What do we know ? Arch Pédiatrie. 2020;27(3):117-118. doi:10.1016/j.arcped.2020.03.001

10. Hagmann SHF. COVID-19 in children: More than meets the eye. Travel Med Infect Dis. 2020:101649. doi:https://doi.org/10.1016/j.tmaid.2020.101649

11. Hong H, Wang Y, Chung H, Chen C. ScienceDirect Clinical characteristics of novel coronavirus disease 2019 (COVID-19 ) in newborns, infants and children. Pediatr Neonatol. 2020;61(2):131-132. doi:10.1016/j.pedneo.2020.03.001

12. Lu X, Zhang L, Du H, et al. SARS-CoV-2 Infection in Children. N Engl J Med . 2020;382(17):16631665. doi:10.1056/NEJMc2005073

13. Ma YL, Xia SY, Wang M, Zhang SM, DU WH, Chen Q. Zhongguo Dang Dai Er Ke Za Zhi . 2020;22(4):290-293

14. Wiersinga WJ, Rhodes A, Cheng AC, Peacock SJ, Prescott HC. Pathophysiology, Transmission, Diagnosis, and Treatment of Coronavirus Disease 2019 (COVID-19): A Review [published online ahead of print, 2020 Jul 10]. JAMA. 2020;10.1001/jama.2020.12839. doi:10.1001/jama.2020.12839

15. Feldstein LR, Rose EB, Horwitz SM, et al. Multisystem Inflammatory Syndrome in U.S. Children and Adolescents [published online ahead of print, 2020 Jun 29]. N Engl J Med. 2020;NEJMoa2021680. doi:10.1056/NEJMoa2021680.

16. Moher D, Liberati A, Tetzlaff J, et al. Preferred reporting items for systematic reviews and metaanalyses: The PRISMA statement. PLoS Med. 2009;6(7). doi:10.1371/journal.pmed.1000097

17. Whittaker E, Bamford A, Kenny J, et al. Clinical Characteristics of 58 Children With a Pediatric Inflammatory Multisystem Syndrome Temporally Associated With SARS-CoV-2 [published online ahead of print, 2020 Jun 8]. JAMA . 2020;e2010369. doi:10.1001/jama.2020.10369.

18. Cheung EW, Zachariah P, Gorelik M, et al. Multisystem Inflammatory Syndrome Related to COVID19 in Previously Healthy Children and Adolescents in New York City [published online ahead of print, 
2020 Jun 8]. JAMA . 2020;e2010374. doi:10.1001/jama.2020.10374.

19. Downes MJ, Brennan ML, Williams HC, Dean RS. Development of a critical appraisal tool to assess the quality of cross-sectional studies (AXIS). BMJ Open. 2016;6(12):1-7. doi:10.1136/bmjopen-2016011458.

20. Nyaga VN, Arbyn M, Aerts M. Metaprop: a Stata command to perform meta-analysis of binomial data. Arch Public Health. 2014;72(1):39. Published 2014 Nov 10. doi:10.1186/2049-3258-72-39.

21. Sun D, Li H, Lu XX, et al. Clinical features of severe pediatric patients with coronavirus disease 2019 in Wuhan: a single center's observational study [published online ahead of print, 2020 Mar 19]. World J Pediatr . 2020;1-9. doi:10.1007/s12519-020-00354.

22. Liu H, Liu F, Li J, Zhang T, Wang D, Lan W. Clinical and CT imaging features of the COVID-19 pneumonia: Focus on pregnant women and children. J Infect . 2020;80(5):e7-e13. doi:10.1016/j.jinf.2020.03.007.

23. Hu Z, Song C, Xu C, et al. Clinical characteristics of 24 asymptomatic infections with COVID19 screened among close contacts in Nanjing, China. Sci China Life Sci . 2020;63(5):706-711. doi:10.1007/s11427-020-1661-4.

24. Li W, Cui H, Li K, Fang Y, Li S. Chest computed tomography in children with COVID-19 respiratory infection. Pediatr Radiol . 2020;50(6):796-799. doi:10.1007/s00247-020-04656-7.

25. Xu Y, Li X, Zhu B, et al. Characteristics of pediatric SARS-CoV-2 infection and potential evidence for persistent fecal viral shedding. Nat Med . 2020;26(4):502-505. doi:10.1038/s41591-020-0817-4.

26. Xia W, Shao J, Guo Y, Peng X, Li Z, Hu D. Clinical and CT features in pediatric patients with COVID-19 infection: Different points from adults. Pediatr Pulmonol . 2020;55(5):1169-1174. doi:10.1002/ppul.24718

27. Zheng F, Liao C, Fan QH, et al. Clinical Characteristics of Children with Coronavirus Disease 2019 in Hubei, China. Curr Med Sci . 2020;40(2):275-280. doi:10.1007/s11596-020-2172-6.

28. Qiu H, Wu J, Hong L, Luo Y, Song Q, Chen D. Clinical and epidemiological features of 36 children with coronavirus disease 2019 (COVID-19) in Zhejiang, China: an observational cohort study.Lancet Infect Dis . 2020;20(6):689-696. doi:10.1016/S1473-3099(20)30198-5.

29. Su L, Ma X, Yu H, et al. The different clinical characteristics of coronavirus disease cases between children and their families in China - the character of children with COVID-19. Emerg Microbes Infect . 2020;9(1):707-713. doi:10.1080/22221751.2020.1744483.

30. Wu Q, Xing Y, Shi L, et al. Coinfection and Other Clinical Characteristics of COVID-19 in Children [published online ahead of print, 2020 May 6]. Pediatrics . 2020;e20200961. doi:10.1542/peds.2020-0961.

31. Dong Y, Mo X, Hu Y, et al. Epidemiology of COVID-19 Among Children in China. Pediatrics . 2020;145(6):e20200702. doi:10.1542/peds.2020-0702.

32. Zhang T, Cui X, Zhao X, et al. Detectable SARS-CoV-2 viral RNA in feces of three children during recovery period of COVID-19 pneumonia.J Med Virol . 2020;92(7):909-914. doi:10.1002/jmv.25795

33. Cai J, Xu J, Lin D, et al. A Case Series of children with 2019 novel coronavirus infection: clinical and epidemiological features [published online ahead of print, 2020 Feb 28]. Clin Infect Dis . 2020;ciaa198. doi:10.1093/cid/ciaa198.

34. Chen C, Cao M, Peng L, et al. Coronavirus Disease-19 Among Children Outside Wuhan, China (2/25/2020). Available at SSRN:http://dx.doi.org/10.2139/ssrn.3546071

35. Wang Y, Zhu F, Wu J. et al. Epidemiological and Clinical Characteristics of 74 Children Infected with SARS-CoV-2 in Family Clusters in Wuhan, China (3/17/2020). Available at SSRN:http://dx.doi.org/10.2139/ssrn.3558012

36. Chen J, Zhang Z-Z, Chen Y-K, et al. The clinical and immunological features of pediatric COVID-19 patients in China. Genes Dis. 2020. doi:https://doi.org/10.1016/j.gendis.2020.03.008

37. Li B, Shen J, Li L, Yu C. Radiographic and Clinical Features of Children with 2019 Novel Coronavirus (COVID-19) Pneumonia. Indian Pediatr. April 2020.

38. See KC, Liew SM, Ng DCE, et al. COVID-19: Four Paediatric Cases in Malaysia. Int J Infect Dis. 2020. doi:https://doi.org/10.1016/j.ijid.2020.03.049

39. Shekerdemian LS, Mahmood NR, Wolfe KK, et al. Characteristics and Outcomes of Children With 
Coronavirus Disease 2019 (COVID-19) Infection Admitted to US and Canadian Pediatric Intensive Care Units [published online ahead of print, 2020 May 11]. JAMA Pediatr . 2020;10.1001/jamapediatrics.2020.1948.doi:10.1001/jamapediatrics.2020.1948

40. Musolino AM, Supino MC, Buonsenso D, et al. Lung Ultrasound in Children with COVID-19: Preliminary Findings [published online ahead of print, 2020 May 3]. Ultrasound Med Biol . 2020;S03015629(20)30198-8. doi:10.1016/j.ultrasmedbio.2020.04.026.

41. Merza MA, Haleem Al Mezori AA, Mohammed HM, Abdulah DM. COVID-19 outbreak in Iraqi Kurdistan: The first report characterizing epidemiological, clinical, laboratory, and radiological findings of the disease [published online ahead of print, 2020 May 5].Diabetes Metab Syndr . 2020;14(4):547-554. doi:10.1016/j.dsx.2020.04.047.

42. Song R, Han B, Song M, et al. Clinical and epidemiological features of COVID-19 family clusters in Beijing, China [published online ahead of print, 2020 Apr 23]. J Infect . 2020;S0163-4453(20)30229-2. doi:10.1016/j.jinf.2020.04.018.

43. Ma H, Hu J, Tian J, et al. A single-center, retrospective study of COVID-19 features in children: a descriptive investigation. BMC Med . 2020;18(1):123. Published 2020 May 6. doi:10.1186/s12916-02001596-9.

44. Verdoni L, Mazza A, Gervasoni A, et al. An outbreak of severe Kawasaki-like disease at the Italian epicentre of the SARS-CoV-2 epidemic: an observational cohort study. Lancet . 2020;395(10239):17711778. doi:10.1016/S0140-6736(20)31103-X.

45. Tan YP, Tan BY, Pan J, Wu J, Zeng SZ, Wei HY. Epidemiologic and clinical characteristics of 10 children with coronavirus disease 2019 in Changsha, China. J Clin Virol . 2020;127:104353. doi:10.1016/j.jcv.2020.104353.

46. Song W, Li J, Zou N, Guan W, Pan J, Xu W. Clinical features of pediatric patients with coronavirus disease (COVID-19). J Clin Virol . 2020;127:104377. doi:10.1016/j.jcv.2020.104377

47. Parri N, Lenge M, Buonsenso D; Coronavirus Infection in Pediatric Emergency Departments (CONFIDENCE) Research Group. Children with Covid-19 in Pediatric Emergency Departments in Italy [published online ahead of print, 2020 May 1]. $N$ Engl J Med . 2020;NEJMc2007617. doi:10.1056/NEJMc2007617.

48. Belhadjer Z, Méot M, Bajolle F, et al. Acute heart failure in multisystem inflammatory syndrome in children (MIS-C) in the context of global SARS-CoV-2 pandemic [published online ahead of print, 2020 May 17]. Circulation . 2020;10.1161/CIRCULATIONAHA.120.048360. doi:10.1161/CIRCULATIONAHA.120.048360.

49. Tagarro A, Epalza C, Santos M, et al. Screening and Severity of Coronavirus Disease 2019 (COVID19) in Children in Madrid, Spain [published online ahead of print, 2020 Apr 8]. JAMA Pediatr . 2020;e201346. doi:10.1001/jamapediatrics.2020.1346.

50. CDC COVID-19 Response Team. Coronavirus Disease 2019 in Children - United States, February 12-April 2, 2020. MMWR Morb Mortal Wkly Rep . 2020;69(14):422-426. Published 2020 Apr 10. doi:10.15585/mmwr.mm6914e4.

51. De Rojas T, Pérez-Martínez A, Cela E, et al. COVID-19 infection in children and adolescents with cancer in Madrid. Pediatr Blood Cancer . 2020;67(7):e28397. doi:10.1002/pbc.28397

52. Shen Q, Guo W, Guo T, et al. Novel coronavirus infection in children outside of Wuhan, China. Pediatr Pulmonol . 2020;55(6):1424-1429. doi:10.1002/ppul.24762.

53. Wang Y, Liu Y, Liu L, Wang X, Luo N, Li L. Clinical Outcomes in 55 Patients with Severe Acute Respiratory Syndrome Coronavirus 2 Who Were Asymptomatic at Hospital Admission in Shenzhen, China. J Infect Dis . 2020;221(11):1770-1774. doi:10.1093/infdis/jiaa119.

54. Zhu L, Wang J, Huang R, et al. Clinical characteristics of a case series of children with coronavirus disease 2019. Pediatr Pulmonol . 2020;55(6):1430-1432. doi:10.1002/ppul.24767.

55. Du W, Yu J, Wang H, et al. Clinical characteristics of COVID-19 in children compared with adults in Shandong Province, China.Infection . 2020;48(3):445-452. doi:10.1007/s15010-020-01427-2.

56. Garazzino S, Montagnani C, Donà D, et al. Multicentre Italian study of SARS-CoV-2 infection in children and adolescents, preliminary data as at 10 April 2020. Euro Surveill . 2020;25(18):2000600. 
doi:10.2807/1560-7917.ES.2020.25.18.2000600.

57. Nicoletti A, Talarico V, Sabetta L, et al. Screening of COVID-19 in children admitted to the hospital for acute problems: preliminary data. Acta Biomed . 2020;91(2):75-79. Published 2020 May 11. doi:10.23750/abm.v91i2.9607.

58. Li Y, Cao J, Zhang X, Liu G, Wu X, Wu B. Chest CT imaging characteristics of COVID-19 pneumonia in preschool children: a retrospective study. BMC Pediatr . 2020;20(1):227. Published 2020 May 18. doi:10.1186/s12887-020-02140-7.

59. DeBiasi RL, Song X, Delaney M, et al. Severe COVID-19 in Children and Young Adults in the Washington, DC Metropolitan Region [published online ahead of print, 2020 May 13]. J Pediatr . 2020;10.1016/j.jpeds.2020.05.007. doi:10.1016/j.jpeds.2020.05.007.

60. Zachariah P, Johnson CL, Halabi KC, et al. Epidemiology, Clinical Features, and Disease Severity in Patients With Coronavirus Disease 2019 (COVID-19) in a Children's Hospital in New York City, New York [published online ahead of print, 2020 Jun 3]. JAMA Pediatr . 2020;e202430. doi:10.1001/jamapediatrics.2020.2430

61. Cabrero-Hernández M, García-Salido A, Leoz-Gordillo I, et al. Severe SARS-CoV-2 Infection in Children With Suspected Acute Abdomen: A Case Series From a Tertiary Hospital in Spain [published online ahead of print, 2020 May 26]. Pediatr Infect Dis J . 2020;10.1097/INF.0000000000002777. doi:10.1097/INF.0000000000002777

62. Toubiana J, Poirault C, Corsia A, et al. Kawasaki-like multisystem inflammatory syndrome in children during the covid-19 pandemic in Paris, France: prospective observational study. BMJ . 2020;369:m2094. Published 2020 Jun 3. doi:10.1136/bmj.m2094

63. Castagnoli R, Votto M, Licari A, et al. Severe Acute Respiratory Syndrome Coronavirus 2 (SARS-CoV-2) Infection in Children and Adolescents: A Systematic Review [published online ahead of print, 2020 Apr 22]. JAMA Pediatr . 2020;10.1001/jamapediatrics.2020.1467. doi:10.1001/jamapediatrics.2020.1467

64. Korean Society of Infectious Diseases; Korean Society of Pediatric Infectious Diseases; Korean Society of Epidemiology; Korean Society for Antimicrobial Therapy; Korean Society for Healthcare-associated Infection Control and Prevention; Korea Centers for Disease Control and Prevention. Report on the Epidemiological Features of Coronavirus Disease 2019 (COVID-19) Outbreak in the Republic of Korea from January 19 to March 2, 2020. J Korean Med Sci . 2020;35(10):e112. Published 2020 Mar 16. doi:10.3346/jkms.2020.35.e112

65. De Souza TH, Nadal JA, Nogueira RJN, Pereira RM, Brandão MB. Clinical manifestations of children with COVID-19: A systematic review [published online ahead of print, 2020 Jun 3]. Pediatr Pulmonol . 2020;10.1002/ppul.24885. doi:10.1002/ppul.24885

66. Posfay-Barbe KM, Wagner N, Gauthey M, et al. COVID-19 in Children and the Dynamics of Infection in Families. Pediatrics. 2020:e20201576. doi:10.1542/peds.2020-1576

67. Jones TC, Mühlemann B, Veith T, et al. An analysis of SARS-CoV-2 viral load by patient age. medRxiv. January 2020:2020.06.08.20125484. doi:10.1101/2020.06.08.20125484

68. García-Salido A. Three Hypotheses About Children COVID19. Pediatr Infect Dis J. 2020;39(7):e157. doi:10.1097/INF.0000000000002701

69. Pathak EB, Salemi JL, Sobers N, Menard J, Hambleton IR. COVID-19 in Children in the United States: Intensive Care Admissions, Estimated Total Infected, and Projected Numbers of Severe Pediatric Cases in 2020. J Public Health Manag Pract. 2020;00(00):1-9. doi:10.1097/PHH.0000000000001190

70. Rodriguez-Morales AJ, Cardona-Ospina JA, Gutiérrez-Ocampo E, et al. Clinical, laboratory and imaging features of COVID-19: A systematic review and meta-analysis [published online ahead of print, 2020 Mar 13]. Travel Med Infect Dis . 2020;101623. doi:10.1016/j.tmaid.2020.101623

Figures and tables.

Figure 1. PRISMA flow chart.

Table 1. General characteristics of included studies. 
Figure 2. Meta-analysis of illness severity.

Figure 3. Meta-analysis of OR. ( $<1 \mathrm{y}$ and severe/critical disease and $>10 \mathrm{y}$ severe/critical disease).

Figure 4 . Meta-analysis of clinical manifestations. (Fever, cough, diarrhea and vomit).

\section{Hosted file}

Table 1. General characetristics of included studies.docx available at https://authorea.com/ users/348331/articles/473715-clinical-features-and-illness-severity-in-children-withcovid-19-a-systematic-review-and-meta-analysis

\section{Hosted file}

Figure 1. PRISMA Flow Chart.pptx available at https://authorea.com/users/348331/articles/ 473715-clinical-features-and-illness-severity-in-children-with-covid-19-a-systematicreview-and-meta-analysis

\section{Hosted file}

Figure 2.Meta-analysis of illness severity.pptx available at https://authorea.com/users/ 348331/articles/473715-clinical-features-and-illness-severity-in-children-with-covid-19a-systematic-review-and-meta-analysis

\section{Hosted file}

Figure 3.Meta-analysisi of OR.pptx available at https://authorea.com/users/348331/articles/ 473715-clinical-features-and-illness-severity-in-children-with-covid-19-a-systematicreview-and-meta-analysis 